\title{
The causes of parental vaccine refusal: results of a survey from Giresun, Turkey
}

\author{
Özlem Terzi ${ }^{1 \oplus}$, Elif Nur Gülen ${ }^{2 \oplus}$, Cihad Dündar ${ }^{1 \oplus}$ \\ ${ }^{1}$ Department of Public Health, Ondokuz Mayıs University Faculty of Medicine, Samsun; ${ }^{2}$ Ministry of Health Giresun Provincial \\ Health Directorate, Giresun, Turkey.
}

\begin{abstract}
Background. While efforts have raised immunization levels in developing countries, high rates of vaccine refusal in both developing and developed countries are causing concern worldwide. We aimed to determine the causes of vaccine refusal among parents refusing or postponing the vaccination of their children.

Methods. This descriptive, cross-sectional study was performed in the Giresun province of Turkey. The study population included families who were unwilling or refused to vaccinate at least one of their children under the scope of the Turkey Enhanced Program of Immunization. Data were obtained during the year 2018 by face-toface interviews with each vaccine hesitant parent (VHP).

Results. Vaccine refusal incidence was $1.2 \%$ in the year 2018 . In 8 (14.8\%) of the children, the vaccination was recorded to be postponed due to health problems, while $46(85.2 \%)$ children were not vaccinated due to parental vaccine refusal. Two-thirds of unvaccinated children were living outside the province center of Giresun. The parents consisted of young adults whose average age was 30.6 \pm 6.6 years. VHPs were mostly university graduates (61.1\% of mothers-70.3\% of fathers). While at least one of the VHPs was a religious official in $24.1 \%$, at least one of the either VHP was a teacher in $20.3 \%$. The most common reasons for vaccine refusal were "fear of vaccine side-effects" (55.6\%), and "problems in previous vaccinations" (33.3\%). In $44.4 \%$ of refusal cases, no specific reason was stated.
\end{abstract}

Conclusions. Primary healthcare providers, who are in close contact with parents, have an important role to provide the right health information. Various in-service training can be provided to improve the communication skills of healthcare providers. In these training sessions, besides comprehensive information about vaccines, it should be aimed to provide parents with the ability to understand their concerns, to approach them sensitively and to present the information they need effectively.

Key words: childhood vaccination, immunization, vaccine hesitant parents, vaccine refusal.

Immunization is one of the most effective public health tools for preventing contagious diseases, reducing mortality and disease rates, ensuring improved health, and eliminating such diseases as smallpox. According to the World Health Organization (WHO), thanks to vaccination procedures, more than 100 million children are inoculated before the age of one year, and 2.5 million child deaths are avoided every year. ${ }^{1,2}$

\section{Cihad Dündar}

cdundar@omu.edu.tr

Received 28th May 2020, revised 1st December 2020, 6th January 2021, 31st January 2021,

accepted 8th February 2021.
While efforts are being made to raise immunization levels in developing countries and in communities with low socioeconomic levels ${ }^{3,4}$, increasing vaccine refusal not only in developing but also in developed countries which have high immunization levels is causing worldwide concern.-7 The latest data from the United States of America (USA) have revealed an increase in alternative vaccination programs in addition to vaccination for preschool children. . $^{3,4}$ Vaccine hesitancy is not a new occurrence, its negative impact on preventive services is gradually increasing. It has been shown that rejection or hesitation of vaccinations are associated with higher socioeconomic status, 
education level of the mother, and shared cultural beliefs which tend to be clustered geographically. ${ }^{8,9}$ Another important reason for this phenomenon is that many vaccinepreventable diseases are not perceived as a serious risk. Since most parents are not familiar with these diseases today, their threats are less tangible and concerns about these diseases have been replaced by the concern of vaccine safety. ${ }^{8}$ In addition to these concerns, the increment of the number of routinely applied vaccines in time became another fear factor for parents who believe that vaccines could affect their children's immune system. ${ }^{10}$

The Turkish Ministry of Health provides all childhood vaccines free of charge within the scope of its Expanded Program on Immunization (EPI). In accordance with the vaccination schedule in the EPI circular issued by the Ministry of Health, family physicians monitor the vaccination times of all children via an electronic record system. ${ }^{11}$ Additionally they remind families not attending the vaccination appointment on time, and provide vaccinations by inviting families to the family health center by telephone or by visiting them at home. ${ }^{12}$ When family health center staff came across a vaccine hesitant parent (VHP), they inform the hesitant parent face to face or by phone and try to convince them to complete the refused or postponed vaccine. VHPs who do not accept the invitation are reported to the District Health Directorate. The vaccination teams of the district health directorate inform VHP's by phone and invite them to the directorate. Those who accept the invitation are interviewed face to face and tried to be persuaded for vaccination. This pursuance is repeated in every vaccination period for $\mathrm{VHP}^{\prime}$ s. Although vaccination rates are rising continuously in Turkey, debates concerning immunization are also becoming more frequent, as in many countries with high immunization rates. While the number of families who refused vaccines in Turkey was 183 in 2011, 913 in 2013, and 5091 in 2015, it has risen to over 10,000 in 2016. ${ }^{13}$ Vaccine refusals, which were rare in our country, grew like an avalanche in 2015 after a prosecutor won the health precaution lawsuit filed in order not to vaccinate his twins. ${ }^{13}$ According to the statement made by the Ministry of Health, the number of families who refused vaccination reached 23,000 in 2018. ${ }^{14}$ The purpose of this study was to determine the causes of vaccine refusal among parents refusing or postponing the vaccination of their children in Giresun, Turkey.

\section{Material and Methods}

This cross-sectional study was performed in the province of Giresun with a population of 454 thousand between 1st January and 31st December of the year 2018. Giresun is a coastal town located in the Black Sea Region of Turkey with a mid-size population and surface area. The health-care services provided in this city are similar to the ones provided in the other cities of Turkey. The number of children scheduled to receive a vaccination was 4428 by the record of the Giresun Provincial Health Directorate in the year 2018. The number of children who were reported as not having been vaccinated due to vaccine refusal or postponement was $55(1.2 \%)$ until the end of the year. The study group consisted of parents who refused or postponed one or more childhood vaccines of their children. According to the Health Ministry's ordinance, family physicians report all parental vaccine refusal cases to the district health directorate at the end of each month. When a new vaccine refusal case is reported by the family physician, the VHP was invited to the district health directorate. Those who refused the invitation were contacted by telephone, both aiming to persuade them for vaccination and also to collect relevant data.

One of the parents refused the phone interview, and the research was carried out with 54 parents. We obtained verbal and written informed consent from all participants. The study received ethical approval from the Ondokuz Mayis University Clinical Research Ethics Committee (KAEK: 1558) on 13 April 2018. 
A questionnaire form developed by a literature review was used as a data collection tool. It was tested on a group that consisted of 25 participants who refused a vaccination in the previous year. After modifying some questions accordingly, the questionnaire was reorganized. This form consisted of 22 open-ended and multiplechoice questions evaluating demographic characteristics and reasons for vaccine refusal. After obtaining verbal and written informed consent, patients were questioned face-to-face or on the telephone. The questionnaire was filled separately for both the participants and their wives or husbands.

Parents who postponed scheduled vaccination or who totally refused one or more childhood vaccines were considered as VHPs.

\section{Statistical analysis}

The continuous data were expressed as mean \pm standard deviation (SD) values. We presented the categorical variables as frequencies with percentages and compared them according to the independent variables using the chi-square test. The p-value less than 0.05 was considered statistically significant. Statistical analyses were performed using the SPSS version 22.0 (IBM Corporation, Armonk, NY, USA) package program.

\section{Results}

Fifty-four of $4428(1.2 \%)$ scheduled children were identified as not having been vaccinated due to vaccine refusal or postponement. In $8 / 54(14.8 \%)$ of these cases, the vaccination was postponed due to health problems, while in 46 children $(85.2 \%)$ the procedure was refused by parents. Health problems reported as cause of vaccination postponement were chickenpox $(n=3)$, allergy $(n=2)$, epileptic seizure $(n=1)$, constipation $(n=1)$, and low birth weight $(n=1)$. The mean age of the children with VHPs was $20.3 \pm 8.5$ months, and 29 of 54 cases (53.7\%) were girls. In addition, $67.3 \%$ of unvaccinated children were living outside of the province center (in villages within the borders of the province Giresun).
The number of children who did not receive any vaccine was nine $(16.7 \%)$. Among the rejected vaccines, pentavalent vaccine (acellular pertussis and tetanus toxoid + inactive polio vaccine + Haemophilus influenza pediatric dose vaccine) (61.8\%), Conjugated Pneumococcal vaccine $(52.7 \%)$ and Oral Polio Vaccine $(50.9 \%)$ took the first three places (Fig. 1).

Most of the participants who were interviewed were mothers $(n=43,79.6 \%)$. Fathers $(16.7 \%)$ or both parents $(3.7 \%)$ were interviewed in the remaining cases. The decision of vaccination refusal of $19(35.2 \%)$ children was made by mothers and in $35(64.8 \%)$ cases by both parents. All VHPs were married, certain sociodemographic characteristics are presented in Table I.

The most common reasons reported by the VHPs were "fear of vaccine side-effects" $(55.6 \%)$, "no reason" (44.4\%), and "some problems experienced by their child after previous vaccinations" (33.3\%) (Table II). Five $(9.1 \%)$ of the parents stated that they refused the vaccination due to the mercury content of vaccine preparations that is believed to cause autism. Experienced problems after vaccinations were swelling and redness (12\%), or pain at the injection site $(16 \%)$, fever $(30 \%)$, headache $(24 \%)$, muscle pain $(13 \%)$ and loss of appetite $(23 \%)$.

At least one of either parent of 13 (24.1\%) children with VHP was a religious official. The rate of refusal of vaccination due to religious beliefs in this group was $30.8 \%$, while the most common reason $(61.5 \%)$ given for refusal was "No reason, I simply do not want my child to be vaccinated".

While the most common refusal reason was "fear of side-effects of all vaccines" (62.5\%) in parents who were health workers, it was "No reason, I simply do not want vaccination" $(43.8 \%)$ in parents who were teachers. Parents living in rural areas $(n=36,54.1 \%)$ stated that they refused to vaccinate because of fear of the side effects of all vaccines. 


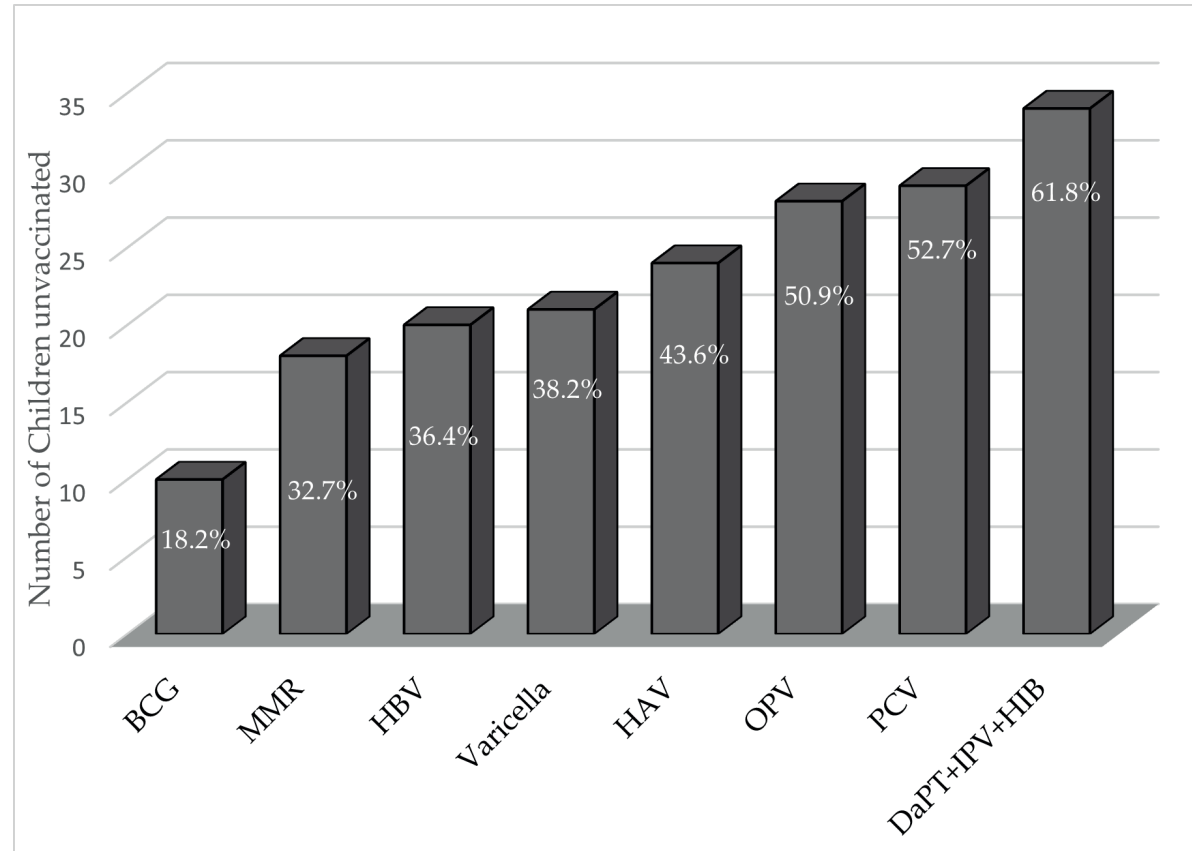

Fig. 1. Vaccines refused or delayed.

BCG: Bacille Calmette-Guérin vaccine, MMR: Measles. Mumps. Rubella vaccine, HBV: Hepatitis B pediatric dose vaccine, Varicella: Varicella vaccine, HAV: Hepatitis A pediatric dose vaccine, OPV: Oral Polio Vaccine, PCV: Pneumococcal conjugate vaccine, DaPT+IPV+HIB: Pentavalent Diphtheria and tetanus toxoid with acellular pertussis + Inactivated polio vaccine + Haemophilus influenza pediatric dose vaccine

Table I. Sociodemographic characteristics of vaccine-hesitant parents.

\begin{tabular}{llcc}
\hline Variables & & Mother (n: 54) & Father (n: 54) \\
\hline Age (year) & & $28 \pm 7$ & $31 \pm 8$ \\
& Elementary & $4(7.4)$ & $1(1.8)$ \\
Graduation & Primary school & $7(13.0)$ & $1(1.8)$ \\
$\mathrm{n}(\%)$ & High school & $10(18.5)$ & $14(25.9)$ \\
& Collage-University & $33(61.1)$ & $38(70.3)$ \\
& None /Unemployed & $32(59.4)$ & $1(1.9)$ \\
Occupation & Health worker & $6(11.1)$ & $2(3.8)$ \\
n (\%) & Religious official & $4(7.4)$ & $11(20.4)$ \\
& Teacher & $8(14.8)$ & $6(11.1)$ \\
& Public sector employee & $3(5.6)$ & $20(36.9)$ \\
\hline
\end{tabular}

\section{Discussion}

To the best of our knowledge, this is the first epidemiological study conducted by a one-toone interview with VHPs in North Anatolian region of Turkey. We found that the VHP rate in our research increased by a third $(1.2 \%)$ compared to the previous year $(0.9 \%)$. In fact, when we review the research carried out on
VHPs, we were expecting a higher incidence. Because survey studies in various countries have reported varying rates of vaccine refusal, from $2 \%$ to $12 \% .5,6,15,16$ One of the reasons for the low incidence in our study may be that it involved parents who were definitely confirmed as VHP. In many studies with high vaccine rejection rates, the data were obtained 
Table II. Vaccine-hesitant parents' reasons for vaccine refusal (n: 54)

\begin{tabular}{lc}
\hline Reasons & $\mathrm{n}^{*}(\%)$ \\
\hline I fear the side-effects of all vaccines & $30(55.6)$ \\
No reason, I simply do not want vaccination & $24(44.4)$ \\
My child experienced some problems after his/her previous vaccinations & $18(33.3)$ \\
My child will not catch the disease requiring this vaccine & $12(22.2)$ \\
I think that the vaccine may be harmful & $9(16.7)$ \\
Due to my child's health problems & $8(14.8)$ \\
I experienced some problems after vaccination & $8(14.8)$ \\
I am opposed to vaccination because of my beliefs & $8(14.8)$ \\
I do not believe that vaccination is beneficial & $7(13.0)$ \\
Leaders/elders/my family/friends are unwilling & $7(13.0)$ \\
My child has already had this disease* & $3(5.6)$ \\
I have needle phobia & $2(3.7)$ \\
\hline
\end{tabular}

*Multiple options are marked. +for chickenpox vaccination only

through self-reports about the participants' attitude and vaccine refusal was not confirmed by medical records. ${ }^{5,17,18}$ Compared to other regions/countries, the other reasons for the lower refusal rate may be that vaccination services in Turkey are provided by the nearest family health center, vaccination is entirely free of charge, and family physicians and nurse practitioners are responsible for monitoring childhood vaccination schedules.

Concern about side effects was the most common reason for vaccine refusal and postponement in our study. In particular, although the perceived link between the vaccine and autism is not supported by reliable scientific evidence, nevertheless, it is a significant factor increasing anxiety over vaccine safety. ${ }^{19,20}$ As shown in our study, there was also a belief in Turkey that vaccines can lead to autism. ${ }^{21}$ Different studies have also shown that parents regard vaccines as having low efficacy and reliability. ${ }^{17,22}$ Giving information on potentially confusing issues such as the efficacy and safety of vaccines by different categories of healthcare professionals can provide a positive impact on parents' decision-making process. ${ }^{6,23}$ It can be considered as a good opportunity for missed vaccines when a child visits a clinic for any reason. After this child's physical examination, the allocation of time to inform the parents about vaccinations will be of great benefit in eliminating vaccine hesitations.

We found that approximately a quarter of parents in our study did not fully perceive the importance of vaccine-preventable diseases. Topçu et al. ${ }^{21}$ reported that $36 \%$ of parents believed that their children would not contract a vaccine-specific disease in Turkey. In a systematic review of factors affecting vaccine uptake in young children, it was reported that many VHPs thought that their children had low susceptibility to such diseases, or that such diseases were of low severity. ${ }^{24}$ Yet two cases of polio, previously thought to have been eradicated, were observed in Europe in 2015, and one technical report described this as a 'warning sign' resulting from vaccine refusal. ${ }^{22}$ Thanks to the high immunization rates among children under five, the majority of vaccinepreventable diseases have fallen to historically low levels particularly in developed countries. Consequently, new generation young parents are thought to be unaware of health problems and threats faced by earlier generations deriving from once widely prevalent contagious infections. The fact that the VHPs constituting the research group consisted of young adults with an average age of 30 years supports this claim. 
Another important reason for vaccine refusal was some health problems experienced after immunization by VHPs' children or relatives. We believe that if the family physicians and the nurse practitioners provide information about the problems that will be experienced after a vaccination and solutions through effective face-to-face communication, then vaccine hesitations will be reduced. For example, the parents of babies crying due to injections may have additional concerns that the baby will experience a negative effect after the injection. The training of a correct procedure for the reduction of pain due to injections, the use of psychological expedients like simply distracting the child at the time of injection, can make a difference and be beneficial. ${ }^{25}$

Another noteworthy finding in the present study were that two-thirds of the VHPs was university graduates, and more than one-fourth of them were teachers. Several studies have also observed greater vaccine refusal in families with higher education levels. ${ }^{6,17,18}$ However, there are some studies that have reported that education level was not significantly linked with vaccine hesitancy. ${ }^{26,27}$ Highly educated individuals are also expected to have a high level of health literacy. Meppelink et al. ${ }^{28}$ showed that people with high health literacy and negative beliefs about childhood vaccination perceive negative information as more persuasive than positive information. That's because anti-vaccination websites often promote alternative medicine, while promoting parents' autonomy and responsibility. We think that the incidence of VHPs can be reduced by ensuring that parents have access to information from reliable sources, even if their health literacy is otherwise high.

The incidence of VHPs due to faith-related objections in the present study was $14.8 \%$. On the other hand, at least one parent of every four unvaccinated children was a religious official. We think that, in an almost entirely Muslim country such as Turkey, vaccine refusal by parents who are also religious officials may have an adverse influence on other members of society. Studies from Africa and Asia suggest that the lower immunization rates in Muslim communities, in particular, may be due to parents avoiding immunization for religious reasons. ${ }^{29,30}$ The most common theological reason for vaccine refusal in Muslim communities has been shown to be using pork containing ingredients in vaccines. ${ }^{31}$ However, a systematic review study showed that participation by religious and traditional leaders has a positive impact in central African countries and places such as Afghanistan, India and Europe. ${ }^{32}$ That study also showed greater increases (> \%20) in knowledge, awareness or attitudes with programs aimed at overcoming the particular concerns of particular groups compared to other activities. In order to relieve the anxiety of religious parents, in addition to the cooperation of religious leaders with health authorities at the national level, in order to reach the local people, especially in rural areas, primary healthcare providers can visit the places of worship and provide parents with face-to-face information or joint meetings with religious officials.

Our main limitation in this study was VHP's were not open to communication. Therefore, the interview may have failed to show the exact underlying cause of vaccination rejection. Additionally, the health problems reported as a reason for postponing the vaccination could not be verified through the health records. Our study group is not representative of the general Turkish population; therefore, future studies should be extended to broader geographic areas and socioeconomic populations.

In conclusion, a proactive strategy should be adopted to protect children from vaccinepreventable diseases. Local health workers, parents, teachers, volunteers, and peer role models are needed to protect every child in the community. If necessary, initiatives such as door-to-door interviews where easing fears that parents may have and reaching every single child should be encouraged and supported. Efforts such as media campaigns, vaccine pro blogs and initiatives focused on 
the most vulnerable population can turn this negative trend into an effective positive era. As a result, we think that understanding the social determinants of vaccine rejection and trying to eliminate vaccine hesitations in our society is essential for improving vaccination rates. Multilevel collaboration can increase vaccination rates, strengthen herd immunity, and prevent vaccine refusal.

\section{Author contribution}

The authors confirm contribution to the paper as follows: study conception and design: ÖT, ENG; data collection: ENG; analysis and interpretation of results: ÖT, ENG, CD; draft manuscript preparation: ÖT, CD; review \& editing, supervision: CD. All authors reviewed the results and approved the final version of the manuscript.

\section{Ethical approval}

The study received ethical approval from the Ondokuz Mayıs University Clinical Research Ethics Committee (KAEK: 1558) on 13 April 2018.

\section{Source of funding}

This research did not receive any specific grant from funding agencies in the public, commercial, or not-for-profit sectors.

\section{Conflicts of interest}

The authors have no conflicts of interest to declare.

\section{REFERENCES}

1. Fine-Goulden M. Should childhood vaccination be compulsory in the UK? Opticon1826 2010. Doi:10.5334/opt.081003.

2. WHO. World Immunization Week 2016: close the immunization gap.Available at http://www.who.int/ campaigns/immunization-week/2016/en/ (Accessed on May 4, 2020).
3. Baguune B, Ndago JA, Adokiya MN. Immunization dropout rate and data quality among children 12-23 months of age in Ghana. Arch Public Health 2017; 75: 18 .

4. Andrews-Chavez J, Biswas A, Gifford M, Eriksson C, Dalal K. Identifying households with low immunisation completion in Bangladesh. Health 2012; 4: 1088-1097.

5. My C, Danchin M, Willaby HW, Pemberton S, Leask J. Parental attitudes, beliefs, behaviours and concerns towards childhood vaccinations in Australia: a national online survey. Aust Fam Physician 2017; 46: 145-151.

6. Frew PM, Fisher AK, Basket MM, et al. Changes in childhood immunization decisions in the United States: results from 2012 \& 2014 National Parental Surveys. Vaccine 2016; 34: 5689-5696.

7. Succi RCM. Vaccine refusal-what we need to know. J Pediatr 2018; 94: 574-581.

8. Gesser-Edelsburg A, Shir-Raz Y, Green MS. Why do parents who usually vaccinate their children hesitate or refuse? General good vs. individual risk. J Risk Res 2016; 19: 405-424.

9. Kelley CA, Velazco CS, Delaney TV, et al. Factors contributing to suboptimal rates of childhood vaccinations in Vermont. J Child Health Care 2015; 19: 558-568.

10. McKee C, Bohannon K. Exploring the reasons behind parental refusal of vaccines. J Pediatr Pharmacol Ther 2016; 21: 104-109.

11. Gülcü S, Arslan S. Çocuklarda aşı uygulamaları: güncel bir gözden geçirme. Düzce Üniversitesi Sağlık Bilimleri Enstitüsü Dergisi 2018; 8: 34-43.

12. Yalçin SS, Bakacak AG, Topaç O. Unvaccinated children as community parasites in National Qualitative Study from Turkey. BMC Public Health 2020; 20: 1087.

13. Bozkurt HB. Aşı reddine genel bir bakış ve literatürün gözden geçirilmesi. Kafkas Tıp Bilimleri Dergisi 2018; 8: 71-76.

14. Üzüm Ö, Eliaçık K, Örsdemir HH, Karadağ Öncel E. Ebeveynlerin aşı yaklaşımlarını etkileyen faktörler: bir eğitim araştırma hastanesine ilişkin değerlendirme. Çocuk Enfeksiyon Dergisi 2019; 13: 144-149.

15. Henrikson NB, Anderson ML, Opel DJ, Dunn J, Marcuse EK, Grossman DC. Longitudinal trends in vaccine hesitancy in a cohort of mothers surveyed in Washington State, 2013-2015. Public Health Rep 2017; 132: 451-454. 
16. Zuzak TJ, Zuzak-Siegrist I, Rist L, Staubli G, SimoesWüst AP. Attitudes towards vaccination: users of complementary and alternative medicine versus non-users. Swiss Med Wkly 2008; 138: 713-718.

17. Napolitano F, D'Alessandro A, Angelillo IF. Investigating Italian parents' vaccine hesitancy: a cross-sectional survey. Hum Vaccin Immunother 2018; 14: 1558-1565.

18. Alsubaie SS, Gosadi IM, Alsaadi BM, et al. Vaccine hesitancy among Saudi parents and its determinants. Results from the WHO SAGE working group on vaccine hesitancy survey tool. Saudi Med J 2019; 40: 1242-1250.

19. DeStefano F. Vaccines and autism: evidence does not support a causal association. Clin Pharmacol Ther 2007; 82: 756-759.

20. Doja A, Roberts W. Immunizations and autism: a review of the literature. Can J Neurol Sci 2006; 33: 341-346.

21. Topçu S, Almış H, Başkan S, Turgut M, Orhon FŞ, Ulukol B. Evaluation of childhood vaccine refusal and hesitancy intentions in Turkey. Indian J Pediatr 2019; 86: 38-43.

22. Salmon DA, Dudley MZ, Glanz JM, Omer SB. Vaccine hesitancy: causes, consequences, and a call to action. Am J Prev Med 2015; 49: S391-S398.

23. Frew PM, Lutz CS. Interventions to increase pediatric vaccine uptake: an overview of recent findings. Hum Vacc Immunother 2017; 13: 2503-2511.

24. Smith LE, Amlôt R, Weinman J, Yiend J, Rubin GJ. A systematic review of factors affecting vaccine uptake in young children. Vaccine 2017; 35: 6059-6069.
25. Petrelli F, Contratti C, Tanzi E, Grappasonni I. Vaccine hesitancy, a public health problem. Ann Ig 2018; 30: 86-103.

26. Repalust A, Šević S, Rihtar S, Štulhofer A. Childhood vaccine refusal and hesitancy intentions in Croatia: insights from a population-based study. Psychol Health Med 2017; 22: 1045-1055.

27. Sweileh WM. Bibliometric analysis of global scientific literature on vaccine hesitancy in peerreviewed journals (1990-2019). BMC Public Health 2020; 20: 1252.

28. Meppelink CS, Smit EG, Fransen ML, Diviani N. I was right about vaccination: confirmation bias and health literacy in online health information seeking. J Health Commun 2019; 24: 129-140.

29. Ahmed A, Lee KS, Bukhsh A, et al. Outbreak of vaccine-preventable diseases in Muslim majority countries. J Infect Public Health 2018; 11: 153-155.

30. Costa JC, Weber AM, Darmstadt GL, Abdalla S, Victora CG. Religious affiliation and immunization coverage in 15 countries in Sub-Saharan Africa. Vaccine 2020; 38: 1160-1169.

31. Padela AI, Furber SW, Kholwadia MA, Moosa E. Dire necessity and transformation: entry-points for modern science in Islamic bioethical assessment of porcine products in vaccines. Bioethics 2014; 28: 5966.

32. Jarrett C, Wilson R, O'Leary M, Eckersberger E, Larson HJ; SAGE Working Group on Vaccine Hesitancy.Strategies for addressing vaccine hesitancy-A systematic review. Vaccine 2015; 33: 4180-4190. 